\title{
Physiological responses to lead and PEG-simulated drought stress in metallicolous and non- metallicolous Matthiola (Brassicaceae) species from Iran
}

Behrooz Salehi-Eskandari ( $\nabla$ behsalehi@gmail.com )

Payam Noor University

Mina Shahbazi Gahrouei

University of Isfahan

Robert S. Boyd

Auburn University

Nishanta Rajakaruna

California Polytechnic State University

Rasoul Ghasemi

Payam Noor University

\section{Research Article}

Keywords: Antioxidant enzyme, Cotolerance, Drought stress, Lead, Matthiola flavida, Osmotic adjustment

Posted Date: September 7th, 2021

DOI: https://doi.org/10.21203/rs.3.rs-855301/v1

License: (c) (1) This work is licensed under a Creative Commons Attribution 4.0 International License.

Read Full License 


\section{Abstract}

\section{Aims}

Plants growing on quarry tailings at the Irankouh $\mathrm{Pb} / \mathrm{Zn}$ mine encounter both drought stress and high levels of $\mathrm{Pb}$. To better understand role of drought and $\mathrm{Pb}$ in plant adaptation to $\mathrm{Pb} / \mathrm{Zn}$ quarry tailings, we compared effects of drought stress (simulated by polyethylene glycol - PEG) and Pb, individually and in concert, to determine how these stressors affected two plant species: the metallicolous species Matthiola flavida and the non-metallicolous $M$. incana.

\section{Methods}

Plants were exposed to $\mathrm{Pb}\left(\mathrm{Pb}\left(\mathrm{NO}_{3}\right)_{2}\right)$ and three levels of $\mathrm{PEG}(0,-0.5$, and $-0.75 \mathrm{MPa})$ in a complete factorial design.

\section{Results}

Lead had non-significant effects on growth and oxidative stress but enhanced levels of osmoprotectants and phenol compounds in the metallicolous $M$. flavida, whereas in the non-metallicolous $M$. incana $\mathrm{Pb}$ had non-significant or toxic effects on the same variables (except for the osmoprotectants proline and glycine betaine, and anthocyanins). In contrast to $M$. incana, the metallicolous species was hypertolerant of $\mathrm{Pb}$, showing strongly reduced root-to-shoot translocation and enhanced $\mathrm{Pb}$ accumulation in the root, especially when under drought stress.

\section{Conclusion}

We conclude that enhanced $\mathrm{Pb}$ accumulation in the root and reduced translocation to the shoot, particularly when under high PEG exposure in the metallicolous species, reduced toxic effects of $\mathrm{Pb}$ in the shoot. This was aided by the accumulation of reducing sugars and phenolic compounds as well as greater catalase activity.

\section{Introduction}

Mine quarry wastes are a challenging plant growth substrate because they create simultaneous stresses: these often include drought stress as well as stress from elevated soil metal levels (Ernst, 1988; Mansfield et al., 2014). Cotolerance, which allows a plant to withstand simultaneous stresses, has been widely studied (de Silva et al., 2012; Nabi et al., 2019; Von Wettberg et al., 2014) but not often in the context of the stresses created by mine quarry wastes. Although tolerance and adaptation to high soil concentrations of heavy metals by plants is metal-specific, and usually those plants cannot tolerate more than one or a few heavy metals (Boyd and Rajakaruna, 2013; Konečná et al., 2020; Singh et al., 2016), the 
stimulation of general stress response pathways by heavy metals may promote cotolerance of other stresses such as drought (Von Wettberg et al., 2014; Selby et al., 2014; Selby and Willis, 2018).

One of the most abundant and toxic heavy metals is $\mathrm{Pb}$, which can have lethal effects on plants, animals, and humans (Fahr et al., 2015; Li et al., 2016; Wani et al., 2015). Lead pollution stems from its widespread uses in industrial activities, including in metal mining/smelting and burning of coal; in energy production ( $\mathrm{Pb}$ in gasoline, emissions from power plants, and use in batteries); from agricultural activities (as ingredient/contaminant in pesticides and fertilizers); as ingredient in ammunition, explosives, and $\mathrm{Pb}$ containing dyes; and its presence in sewage sludge and wastewaters (Gupta et al., 2013; Kumar et al., 2012; Mahdavian et al., 2016).

Lead is a non-essential element for plants and produces many phytotoxic effects, including harm to morphological, biochemical, and physiological processes (Pourrut et al., 2013; Zulfiqar et al., 2019). Some plant species, termed metallophytes by Baker (1987), can survive and reproduce on the intensely metalenriched soils found on metal mine sites. Quarry tailings present around a mining area often are severely polluted by heavy metals (such as $\mathrm{Pb}$ ) and are characterized by other stresses such as lack of water holding capacity, deficiencies of essential nutrients, and low amounts of soil organic matter, and as a consequence are often poorly vegetated (Ghasemi et al., 2018; Mansfield et al., 2014).

The Irankouh $\mathrm{Pb} / \mathrm{Zn}$ mine is located in the semiarid region of Central Iran at $51^{\circ} 42^{\prime} \mathrm{E}$ and $32^{\circ} 30^{\prime} \mathrm{N}$. Therefore, plants in this mine area encounter not only heavy metal stress but also drought stress. Drought stress reduces plant growth by affecting various physiological and biochemical processes, such as water relations, nutrient uptake, leaf chlorophyll levels, photosynthesis, water content, and others (Farooq et al., 2012; Okunlola et al., 2017). Plants can ameliorate drought stress through osmotic adjustment, which is promoted by the production and accumulation of soluble carbohydrates, sucrose, proline, glycine betaine, and other solutes that help maintain cell turgor (Cvikrová et al., 2013; Salehi-Eskandari et al., 2017). Drought stress, like other stresses, stimulates reactive oxygen species (ROS) generation, which induces oxidative damage to cellular components and photoinhibition (Agrawal et al., 2016; Ashraf and Harris, 2013; Cruz de Carvalho, 2008; You and Chan, 2015). To protect from oxidative stress, plants possess antioxidant scavenger systems which can be classified into two broad categories: antioxidant enzymes, such as catalase (CAT), superoxide dismutases (SOD), and ascorbate peroxidase (APX), and nonenzymatic antioxidants such as glutathione, ascorbate, proline, flavonoids, phenolics, a-tocopherol, and carotenoids (Kısa et al., 2016; Salehi-Eskandari et al., 2017).

Matthiola flavida Boiss. (Brassicaceae) is a perennial herb that grows on dry rocky hills and sandy plains in Iran, Pakistan, Kashmir, Afghanistan, and Turcomania (Mohtadi, 2014; Sarwar and Qaiser, 2012). It has been suggested to be useful for phytoremediation of soils contaminated with Pb (Mohtadi et al., 2012a, b). In addition, by adding Fe (Heidari Dehno and Mohtadi, 2018) and the synthetic and biodegradable chelator (S,S)-N,N'-ethylenediamine disuccinic acid (EDDS), hydroponically grown M. flavida accumulates even more $\mathrm{Pb}$ in its shoot tissue (Mohtadi et al., 2013). Despite the generally lethal effect of Pb on plants, $\mathrm{Pb}$ hypertolerance mechanisms, and the combined effects of drought stress with $\mathrm{Pb}$ stress on plant 
physiology, have not been well studied. Therefore, to better understand these effects and particularly their interactions, we studied $\mathrm{Pb}$ stress and drought stress induced by polyethylene glycol (PEG) in the metallicolous species Matthiola flavida and the congeneric non-metallicolous M. incana (L.) R.Br. The species were compared for $\mathrm{Pb}$ uptake and translocation, plant growth (dry weight [DW] biomass and relative water content [RWC]), pigments (carotenoids, chlorophylls a and b), osmotic molecules (proline, glycine betaine, reducing sugars), phenolic compounds (anthocyanin, total phenols), and activities of two antioxidant enzymes, catalase (CAT) and ascorbate peroxidase (APX).

\section{Materials And Methods}

\section{Plant materials and treatment}

About 5000 seeds of the metallicolous Matthiola flavida were collected from a population of about 300 plants growing at the Irankouh $\mathrm{Pb} / \mathrm{Zn}$ mining site, and seeds of a non-metallicolous species, $M$. incana, were provided from a commercial supplier (Pakan Bazr Co., Isfahan, Iran). Matthiola incana was selected as a comparative non-metallicolous species because it has a close phylogenetic position within the genus to M. flavida (Jaén-Molina et al., 2009). Seeds of both species were surface-sterilized using $1 \%$ ( $\mathrm{v} / \mathrm{v}$ ) sodium hypochlorite (bleach) for $15 \mathrm{~min}$, rinsed twice with distilled water, and germinated on Perlite wetted with deionized water. After three weeks, seedlings were transferred to hydroponic culture in $450 \mathrm{ml}$ light-proof vessels (two plants per vessel) containing a modified one-fourth-strength Hoagland's solution composed of $1.5 \mathrm{mM} \mathrm{Ca}\left(\mathrm{NO}_{3}\right)_{2}, 0.75 \mathrm{mM} \mathrm{MgSO}_{4}, 1.25 \mathrm{mM} \mathrm{KNO}_{3}, 0.28 \mathrm{mM} \mathrm{KH}_{2} \mathrm{PO}_{4}, 10 \mu \mathrm{M} \mathrm{Fe}(\mathrm{Na})$-EDTA, $1 \mu \mathrm{M} \mathrm{ZnSO}_{4}, 0.5 \mu \mathrm{M} \mathrm{CuSO}_{4}, 5 \mu \mathrm{M} \mathrm{MnSO}_{4}, 25 \mu \mathrm{M} \mathrm{H}_{3} \mathrm{BO}_{3}, 0.1 \mu \mathrm{M} \mathrm{Na}_{2} \mathrm{MoO}_{4}$, and $50 \mu \mathrm{M} \mathrm{KCl}$. Final pH was adjusted to 5.8 and nutrient solutions were renewed twice a week. Experiments were performed in a greenhouse with a day/night temperature of $25 / 20^{\circ} \mathrm{C}$ and $16 \mathrm{~h}$ photoperiod (light intensity $200 \mu \mathrm{Em}^{-2}$ $\left.\mathrm{s}^{-1}\right)$.

Because the species differed in $\mathrm{Pb}$ tolerance, the $\mathrm{Pb}$-added treatment for each species was selected as the concentration of $\mathrm{Pb}$ to which exposure induced $\mathrm{Pb}$ toxicity symptoms (reduced growth, chlorosis, etc.) for that species. Based on results of prior experiments, $75 \mathrm{mg} \mathrm{L}^{-1}$ and $150 \mathrm{mg} \mathrm{L}^{-1}$ were selected as the concentrations of $\mathrm{Pb}\left(\mathrm{NO}_{3}\right)_{2}$ sufficient to produce toxicity symptoms for the non-metallicolous $M$. incana and the metallicolous $M$. flavida, respectively. After 45 days for $M$. incana, and 60 days for $M$. flavida, half of the vessels for each species received nutrient solution amended with $\mathrm{Pb}\left(\mathrm{NO}_{3}\right)_{2}$. To avoid precipitation of $\mathrm{Pb}$ phosphate and formation of $\mathrm{Pb}$-EDTA resulting from $\mathrm{Pb}$ replacing Fe from the EDTA complex in the $\mathrm{Pb}$-added solutions, the $\mathrm{KH}_{2} \mathrm{PO}_{4}$ and $\mathrm{Fe}(\mathrm{Na})$-EDTA were removed. They were also removed from the nutrient solutions of the no $\mathrm{Pb}$-added treatments to make the solutions as similar to one another as possible.

After another 7 days, all pots were additionally modified with $0 \%, 13.8 \%$, or $23.3 \%$ of polyethylene glycol 6000 (PEG, w/v), equivalent to osmotic potentials of $0,-0.25$, and $-0.75 \mathrm{MPa}$, respectively (Money, 1989). To avoid osmotic shock, PEG was added in $0.25 \mathrm{MPa}$ steps at $6 \mathrm{~h}$ intervals until the desired 
concentration was reached. Nutrient solutions were aerated constantly and replaced every three days during the 14 day treatment period.

Each combination of the $\mathrm{Pb}$ and drought stress treatments had six pots (replicates) for each species. Three replicates were harvested for measurements of plant growth and $\mathrm{Pb}$ accumulation, and the other three were used to provide plant material for measuring physiological parameters.

\section{Plant growth and $\mathrm{Pb}$ accumulation}

After harvesting, plants were separated into root and shoot portions and rinsed three times in deionized water, fresh weight (FW) was measured, and dry weight (RDW, root dry weight, and SDW, shoot dry weight) was measured after drying samples at $70^{\circ} \mathrm{C}$ for $48 \mathrm{~h}$ in an oven. Plant water content (WC) was calculated as percent water from the FW and dry weight data. Lead concentrations were determined in shoots and roots by digesting $0.1 \mathrm{~g}$ of dried ground plant material in a $1 / 4(\mathrm{v} / \mathrm{v})$ mixture of $37 \%(\mathrm{v} / \mathrm{v}) \mathrm{HCl}$ and $65 \%(\mathrm{v} / \mathrm{v}) \mathrm{HNO}_{3}$, and $\mathrm{Pb}$ was determined using a flame atomic absorption spectrophotometer (AAS, Shimadzu model 6200). $\mathrm{Pb}$ translocation factors (TFs) were calculated as $\mathrm{Pb}$ concentration in shoots divided by $\mathrm{Pb}$ concentration in roots (Salehi-Eskandari et al., 2018).

\section{Photosynthetic pigments measurement}

The youngest mature leaves (4-5th leaf from the apex) of plants in replicates used for physiological measurements were extracted in $80 \%(\mathrm{v} / \mathrm{v})$ acetone. Total chlorophyll, as well as chlorophyll a, chlorophyll $b$, and carotenoids contents, were measured by spectrophotometry according to Lichtenthaler and Wellburn (1983).

\section{Proline, glycine betaine, and total reducing sugar measurements}

Free proline was extracted from fresh leaves from replicates used for physiological measurements and determined according to Bates et al. (1973). Glycine betaine was extracted from powdered dried leaves and content calculated following the method of Grieve and Grattan (1983). The amount of total reducing sugars (RS) was measured in fresh leaves as defined in Somogyi (1952).

\section{Measurement of anthocyanins and total phenolic contents}

Anthocyanins were extracted from fresh leaves from replicates used for physiological measurements with acidified methanol (methanol: $\mathrm{HCl}, 99: 1 \mathrm{v} / \mathrm{v}$ ). Anthocyanins were measured spectrophotometrically and contents calculated using an extinction coefficient of $33,000 \mathrm{~mol}^{-1} \mathrm{~cm}^{-1}$ (Wanger, 1979). Total phenolic contents were determined using Folin-Ciocalteu reagent according to the method of Velioglu et al. (1998).

\section{Enzyme assays}


One gram of fresh leaf samples was homogenized in $3 \mathrm{ml}$ of cold $50 \mathrm{mM}$ potassium phosphate buffer (pH 7.8), including $0.2 \mathrm{mM}$ EDTA and $2 \%(\mathrm{w} / \mathrm{v})$ polyvinylpyrrolidone (PVP), in an ice bath. The homogenate was centrifuged at $13,000 \mathrm{rpm}$ at $4{ }^{\circ} \mathrm{C}$ for $20 \mathrm{~min}$ and the supernatant used for enzyme activity assays. CAT activity was determined and expressed using the UV spectrophotometric method of Aebi (1984). Ascorbate peroxidase activity was determined based on the method of Asada and Takahashi (1987).

\section{Statistical analysis}

The experiment used a randomized complete block design with three replications for plant growth and $\mathrm{Pb}$ accumulation measurements, and three for physiological parameters. Data analysis was accomplished using SPSS (version 16, for Windows; SPSS Inc., Chicago, IL, USA). Data were analyzed using three-way ANOVA, with $\mathrm{Pb}, \mathrm{PEG}$, and Species as fixed main factors. Individual means were compared using Duncan's test with $\mathrm{P}<0.05$ as a significance threshold. Since our main goal is to compare responses of the metallicolous $M$. flavida against those of the non-metallicolous $M$. incana, we will focus mostly on the Species factor and its two- and three-way interactions with Pb and PEG.

\section{Results}

\section{Plant growth and shoot relative water content}

The Species factor was significant for all growth measures (Table 1), as $M$. incana plants were larger than M. flavida plants and had greater relative water contents (Fig. 1). PEG significantly reduced all growth measures (Fig. 1, Table 1). The species responded similarly to PEG for RDW, as the PEG*Species interaction was not significant (Table 1), but the PEG*Species interaction was significant for SDW and RWC (Table 1). The significant SDW interaction is explained by the relative stability of SDW for $M$. flavida as PEG concentrations increased (Fig. 1D), whereas SDW declined for $M$. incana as PEG concentrations increased (Fig. 1C). For RWC the significant interaction was due to an opposite pattern, with RWC declining in $M$. flavida as PEG concentrations increased (Fig. 1F), whereas RWC was more stable as PEG concentrations increased for M. incana (Fig. 1E). 
Table 1

Significance of the effects of the main factors $\mathrm{Pb}, \mathrm{PEG}$, and Species, and their interactions, on root dry weight (RDW), shoot dry weight (SDW), relative water content (RWC), Pb concentration in roots $(\mathrm{Pb} R$ ) and shoots $(\mathrm{Pb} \mathrm{S}), \mathrm{Pb}$ root-to-shoot translocation $(\mathrm{Pb} \mathrm{S} / \mathrm{R})$, total chlorophyll (Total chl), chorophyll a/b ratio $(\mathrm{Chl} \mathrm{a/b)}$, carotenoids (Car), proline (Pro), glycine betaine (GB), reducing sugar (RS), anthocyanins (Anth), total phenolic concentrations (Phenol), catalase (CAT), and ascorbate peroxidase (APX).

\begin{tabular}{|c|c|c|c|c|c|c|c|}
\hline & Species & PEG & $\mathrm{Pb}$ & Species*PEG & Species*Pb & PEG*Pb & Species*PEG*Pb \\
\hline RDW & $\star * *$ & $\star \star *$ & $\star *$ & NS & ** & NS & NS \\
\hline SDW & $\star \star \star *$ & $\star \star \star *$ & ** & ** & $\star \star \star *$ & NS & NS \\
\hline RWC & $\star \star \star *$ & $\star \star \star$ & NS & $\star \star \star \star ~$ & NS & NS & NS \\
\hline $\mathrm{Pb} \mathrm{R}$ & $\star * \star$ & ** & $\star \star \star *$ & ** & $\star \star \star *$ & ** & ** \\
\hline $\mathrm{Pb} \mathrm{S}$ & $\star \star *$ & ** & $\star \star \star *$ & ** & $\star \star \star *$ & ** & $\star \star$ \\
\hline $\mathrm{Pb} \mathrm{S} / \mathrm{R}$ & $\star \star \star$ & NS & $\star \star \star$ & * & $\star \star \star *$ & NS & * \\
\hline Total chl & NS & $\star \star \star ~$ & $\star \star \star$ & * & NS & * & NS \\
\hline $\mathrm{Chl} \mathrm{a/b}$ & $\star \star \star *$ & $\star \star \star$ & NS & 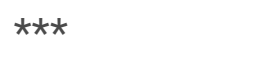 & NS & ** & NS \\
\hline Car & ** & $\star \star \star *$ & $\star \star \star$ & * & ** & NS & * \\
\hline Pro & NS & $\star \star \star ~$ & $\star \star \star$ & $\star \star \star \star ~$ & $\star \star \star$ & ** & ** \\
\hline GB & NS & *** & $\star \star \star$ & * & NS & NS & NS \\
\hline RS & 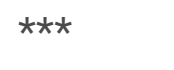 & *** & $\star \star \star \star$ & NS & ** & NS & * \\
\hline Anth & $\star \star * *$ & $\star \star \star ~$ & NS & ** & NS & * & * \\
\hline Phenol & $\star \star * *$ & ** & NS & 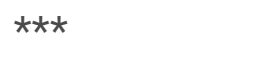 & NS & NS & NS \\
\hline CAT & * & * & $\star \star$ & * & $\star \star$ & NS & NS \\
\hline APX & 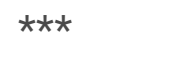 & NS & NS & NS & NS & NS & NS \\
\hline
\end{tabular}

Significance was determined using three-way ANOVA, with Pb, PEG, and Species as main factors (*** $\mathrm{P}<0.001$, ** $\mathrm{P}<0.01$ and $* \mathrm{P}<0.05$, NS = not significant).

The main factor of Pb was significant for SDW and RDW but not RWC (Table 1). The Species*Pb interaction for RDW and SDW was significant because for $M$. incana there were significant adverse effects of $\mathrm{Pb}$ on RDW and SDW whereas for M. flavida Pb had no effect (Fig. 1A-D). The Species*Pb interaction for RWC was not significant because there were no effects of $\mathrm{Pb}$ on $M$. incana and for $M$. flavida $\mathrm{Pb}$ had a positive effect on RWC only in the $-0.25 \mathrm{MPa}$ treatment (Fig. 1E, F).

The Pb*PEG interaction and the Species*PEG*Pb interaction were insignificant for RDW, SDW, and RWC (Table 1), showing that the species responded similarly to combined Pb and PEG treatments.

\section{Lead concentrations}


Responses to $\mathrm{Pb}$ were relatively complex, with significant main effects and interactions for $\mathrm{Pb}$ in shoots, $\mathrm{Pb}$ in roots, and the $\mathrm{Pb}$ shoot/root ratio with the exceptions of non-significance for $\mathrm{Pb}$ shoot/root ratio for $\mathrm{PEG}$ and the PEG*Pb interaction (Table 1). Lead concentrations in the metallicolous $M$. flavida were consistently greater in roots (20.6-, 23.1-, 30.1-fold) and shoots (10.5-, 11-, 9.4-fold) at PEG treatments of $0,-0.25$, and $-0.75 \mathrm{MPa}$ compared to those in the non-metallicolous $M$. incana, resulting in an approximately 2.4 -fold difference in the root-to-shoot translocation factor between the species (Fig. $2 \mathrm{C}$, $\mathrm{D})$. The concentration of root $\mathrm{Pb}$, and the $\mathrm{Pb}$ root-to-shoot translocation factor, were marginally but significantly $(P<0.05)$ affected by PEG in M. flavida (Fig. $2 \mathrm{~B}, \mathrm{D})$ yet were unaffected by PEG in $M$. incana (Fig. $2 \mathrm{~A}, \mathrm{C}$ ), resulting in a significant Species*PEG interaction for $\mathrm{Pb} \mathrm{R}$ and $\mathrm{Pb} \mathrm{S} / \mathrm{R}$ but not for $P E G * P b$ for the $\mathrm{Pb} S / R$ variable (Table 1 ).

\section{Photosynthetic pigments}

Total chlorophyll concentration did not significantly differ between species (the Species factor was nonsignificant) but was greatly reduced by both PEG and Pb (Table 1, Fig. 3). Lead decreased total chlorophyll in $M$. incana (except in the $-0.75 \mathrm{MPa}$ treatment) and strongly decreased it for all three PEG treatments in $M$. flavida, resulting in a significant PEG*Pb interaction (Table 1). The Species*PEG*Pb interaction was insignificant for total chlorophyll (Table 1).

The species differed significantly in chlorophyll a/b ratio (the Species factor was highly significant: Table 1) with greater values for $M$. incana compared to M. flavida at all PEG treatments (Fig. 1 C, D). The main factor of $\mathrm{Pb}$ did not significantly affect chlorophyll $\mathrm{a} / \mathrm{b}$ ratio, but PEG significantly affected chlorophyll $\mathrm{a} / \mathrm{b}$ ratio and there was a significant Species*PEG interaction (Table 1). The interaction is explained by PEG significantly decreasing the chlorophyll a/b ratio in $M$. incana (Fig. $3 \mathrm{C}$ ) but having little effect on $M$. flavida (Fig. 3 D). Lead treatment increased the chlorophyll a/b ratio only for the control treatment in both species (Fig. 3 C, D), resulting in a significant PEG* Pb interaction (Table 1). The Species*PEG*Pb interaction was insignificant (Table 1).

The effects of PEG and Pb on carotenoid concentration mostly followed the patterns observed for total chlorophyll. However, the Species*PEG*Pb interaction was significant (Table 1) which was due to alleviation of the Pb effect by PEG treatments in M. incana (Fig. $3 \mathrm{E}$ ).

\section{Proline, glycine betaine, and total reducing sugars}

Proline concentrations were significantly enhanced by PEG in both species (Fig. 4 A, B), resulting in a significant main effect of PEG (Table 1). However, the significant Species*PEG interaction (Table 1) showed that the degree of enhancement differed between species, with $M$. incana responding more strongly than M. flavida as PEG water potential decreased (Fig. 4 A, B). Lead enhanced proline concentrations in both species, resulting in a significant $\mathrm{Pb}$ main effect (Table 1), but did not affect proline concentrations in the control treatment in both species and the -0.25 MPa PEG treatment in $M$. flavida (Fig. 4 B). Thus, the Species*Pb interaction and the Species*PEG*Pb interaction were significant (Table 1). 
Glycine betaine (GB) concentrations were similar in both species, resulting in an insignificant Species main effect (Table 1). The PEG main effect was also significant (Table 1) with concentrations increasing in both species as PEG water potential decreased (Fig. 4 C, D). There was also a significant Species*PEG interaction (Table 1), as GB was increased by PEG in both species but the increase was greater for $M$. incana than in M. flavida for the most extreme (-0.75 MPa) drought treatment (Fig. 4 C, D).

Reducing sugar (RS) concentrations were significantly affected by all three main factors (Table 1). The Species factor was significant because $M$. incana RS concentrations were greater than in M. flavida (Fig. 4 E, F). PEG generally increased RS concentrations for both species (Fig. 4 E, F), as did Pb (Fig. 4 E, F), but there were significant Species* $\mathrm{Pb}$ and Species*PEG*Pb interactions (Table 1). The significant interactions stemmed from increased RS concentrations due to PEG treatment in both species, but they increased in different concentration-dependent ways between species (Fig. 4 E, F). Lead increased RS concentrations for all PEG treatments for $M$. flavida (Fig. 4 F), but only did so for the control PEG treatment in $M$. incana (Fig. $4 \mathrm{E}$ ). The magnitude of the $\mathrm{Pb}$ effect was generally greater for $\mathrm{M}$. flavida, particularly in the -0.75 MPa PEG treatment (Fig. 4 E), which resulted in a significant Species*PEG*Pb interaction (Table 1).

\section{Anthocyanins and total phenolic contents}

Anthocyanins concentrations were significantly affected by the Species and PEG main factors but not by $\mathrm{Pb}$ (Table 1). Anthocyanins concentrations were much greater in $M$. flavida than $M$. incana but generally increased with decreasing PEG water potential in both species (Fig. 5 A, B). Anthocyanins concentrations in $M$. incana were relatively similar across PEG treaments (Fig. $5 \mathrm{~A}$ ) yet they increased relative to the control for M. flavida in the -0.25 and $-0.75 \mathrm{MPa}$ PEG water potential treatments (Fig. $5 \mathrm{~B}$ ), resulting in a significant Species*PEG interaction (Table 1). The significant Species*PEG*Pb interaction (Table 1) showed that while $\mathrm{Pb}$ as a main factor was not significant, the species differed in how the combination of PEG and Pb affected anthocyanins. This difference was most evident in the highest PEG treatment, for which $M$. incana showed a greater increase in anthocyanins when treated with $\mathrm{Pb}$ than M. flavida (Fig. 5 A, B).

Similar to anthocyanins, total phenolic contents were significantly affected by the Species and PEG main factors but not by $\mathrm{Pb}$ (Table 1). Total phenolic contents also were much greater in $M$. flavida than $M$. incana and generally increased with decreasing PEG water potential (Fig. 5 C, D). There was a significant Species*PEG interaction (Table 1), which resulted from PEG increasing total phenolic contents in different concentration-dependent ways. In $M$. incana, values for both the -0.25 and $-0.75 \mathrm{MPa}$ treatments were greatly increased relative to those for the control treatment (Fig. $5 \mathrm{C}$ ), whereas for M. flavida there was a more stepwise increase in total phenolic contents as PEG water potentials decreased (Fig. 5 D). Unlike anthocyanin concentrations, other interactions were not significant for total phenolic contents (Table 1).

\section{Antioxidant enzymes}

CAT activity was significantly (but relatively weakly) affected by Species and PEG but more strongly by $\mathrm{Pb}$ (Table 1). There also were significant Species*PEG and Species*Pb interactions (Table 1). The 
significant Species*PEG interaction resulted from CAT activity showing no significant changes for the PEG treatments in $M$. incana, but in M. flavida CAT activity increased in the -0.75 MPa PEG treatment (Fig. $6 \mathrm{~B})$. The significant Species* $\mathrm{Pb}$ interaction stemmed from PEG treatments with $\mathrm{Pb}$ consistently decreasing CAT activity compared to the same treatments without PEG (except in the control treatment) for M. incana (Fig. $6 \mathrm{~B}$ ). In contrast, for M. flavida PEG treatments with $\mathrm{Pb}$ added to the nutrient solution enhanced CAT activity except in the control treatment (Fig. 6 A).

The other examined antioxidant enzyme, APX, was highly affected by the Species factor but not by other factors or factor interactions (Table 1). APX activity was generally much greater in $M$. flavida than in $M$. incana regardless of PEG or Pb treatments (Fig. $6 \mathrm{C}, \mathrm{D}$ ).

\section{Discussion}

Drought stress in arid and semiarid habitats can severely reduce plant growth, change plant chemical composition, and reduce seed quantity and plant survival (Osakabe et al., 2014; Zhang et al., 2018). A common adverse effect of drought stress on plants is reduction of fresh and dry biomass due to decreased numbers and sizes of leaves, which results from reduced plant water potential, increased oxidative stress, and limited photosynthesis (Sharma et al., 2020; Wang et al., 2018). These growth responses help reduce water loss from plants under drought stress (Anjum et al., 2011; Farooq et al., 2009; Hajihashemi and Sofo, 2018). Indeed, any factor that stimulates drought resistance in plants will increase fitness under conditions of low water availability. Our results showed that growth indices (including RDW, SDW, and RWC) decreased gradually with increased PEG concentration in both species. The highly significant Species* $\mathrm{Pb}$ interaction for SDW stemmed from the high level of $\mathrm{Pb}$ tolerance by $M$. flavida. In the presence of $\mathrm{Pb}$, growth indices for the metallicolous $M$. flavida generally were unchanged by PEG treatments compared to the same treatments without Pb, except that RWC was increased for $M$. flavida in the - 0.25 MPa PEG with Pb treatment (Fig. 1). In contrast, Pb consistently decreased growth indices in the non-metallicolous species (M. incana) compared to the same PEG treatments without $\mathrm{Pb}$, except for RWC (Fig. 1).

Mohtadi et al. (2012b) reported M. flavida as a $\mathrm{Pb}$ hyperaccumulator that grows on metalliferous soils and can contain $>1 \mathrm{mg} \mathrm{g}^{-1}$ ( $0.1 \%$ dry weight) $\mathrm{Pb}$ in the shoot without suffering phytotoxic effects (Rascio and Navari-Izzo, 2011). In our results (Fig. 2), Pb concentration was consistently greater in M. flavida than in M. incana. In both species $\mathrm{Pb}$ concentration in the root was several-fold higher than in the shoot, showing that most $\mathrm{Pb}$ was absorbed by roots but excluded from transport to shoots. Restricting metal to roots has been reported as a mechanism to avoid Pb toxicity in several plant species (Ginn et al., 2008; Krzesłowska et al., 2010; Mahdavian et al., 2016; Zheng et al., 2012). On the other hand, root Pb concentration was significantly increased by PEG, and the Pb translocation factor (Fig. 2C, D) was reduced in the $-0.75 \mathrm{MPa}$ PEG treatment in the metallicolous $M$. flavida, but not in $M$. incana. In $M$. incana there were adverse additive effects of $\mathrm{Pb}$ and $\mathrm{PEG}$ treatments on growth parameters (Fig. 1). Phytotoxicity of $\mathrm{Pb}$ can be due to its interference with plant water balance and nutrient uptake (Ekmekçi et al., 2009; Hakeem et al., 2019) and can result in reduced cell division and elongation (Dalla Vecchia et 
al., 2005; Mondal et al., 2015). De Silva et al. (2012) observed similar responses to heavy metal toxicity and drought stress, which they measured by xylem conductivity properties. They concluded that responses of plants to heavy metal toxicity were identical to responses to drought, as heavy metal toxicity reduces water uptake and transport capacity in plants.

Why M. flavida fell so short of hyperaccumulation levels in hydroponic cultivation needs additional study. It will be important to investigate if the plants will eventually hyperaccumulate $\mathrm{Pb}$ if grown for longer than the 14-day period we used in the current study. Our results indicate that M. flavida preferentially accumulates $\mathrm{Pb}$ in the root and acts as an excluder, despite being able to translocate and detoxify $\mathrm{Pb}$ in the shoot. It is unclear if, given more time than in our 14-day experiment, it can reach hyperaccumulation levels for Pb as previously shown by Mohtadi et al. (2012a), despite the low TF we documented in this study. For most metals, hyperaccumulators have TF $>1$. Sequestration of toxic metals in hyperaccumulator leaves has been suggested as a mechanism for protecting sensitive roots from metal toxicity, and TF $>1$ has been proposed as a defining feature of hyperaccumulation (Kazakou et al., 2008). Lead is extremely toxic compared to most metals, especially for shoots, and all plants restrict translocation of $\mathrm{Pb}$ (Gupta et al., 2013; Huang et al., 2012). Our study shows that even the metallophyte and documented hyperaccumulator M. flavida (Mohtadi et al. 2012a) can have a low TF ( 0.15) and the ability to restrict translocation even further under $\mathrm{Pb}$ stress.

PEG and Pb had adverse additive effects on photosynthetic pigments in both species (Fig. 3). Drought stress can enhance degradation of photosynthetic pigments because of oxidative stress (Basal et al., 2020; Hajihashemi and Sofo, 2018). Lead prevents the function of chlorophyll synthase by displacing beneficial divalent ions $\left(\mathrm{Mg}^{2+}, \mathrm{Fe}^{2+}\right)$, thereby inducing both ion deficiency and elevated ROS production (Kumar and Prasad, 2018; Li et al., 2016). Lead significantly increased the chlorophyll a/b ratio in the control (0 MPa) PEG treatment for both species, suggesting that chlorophyll $b$ appears to be more sensitive to $\mathrm{Pb}$ than chlorophyll a (Stiborova et al., 1986; Vodnik et al., 1999).

Accumulation of solutes such as soluble sugars, glycine betaine, proline, etc. under water stress not only helps maintain turgor pressure but also protects the quaternary structure of macromolecules from the adverse effects of ROS (Cechin et al., 2006; Miri and Armin, 2013). Measured solute concentrations were increased by PEG but were more strongly enhanced by Pb in both species (Fig. 4), except for reducing sugars, which only increased in response to combinations of Pb and PEG in the metallicolous M. flavida. Accumulation of solutes due to $\mathrm{Pb}$ stress contributes to an osmotic balance that allows a plant to minimize sufficient storage reserves to support basal metabolism under Pb-stressed conditions (Hakeem et al., 2019).

Phenolic compounds (including anthocyanins) have carboxyl and hydroxyl groups that bind heavy metals and are responsible for ROS scavenging in stressed plants (KIsa et al., 2016; Michalak, 2006). Phenolic compounds were increased by PEG treatments in both species (Fig. 5). Lead also increased phenolics in the metallicolous M. flavida but only in the $-0.75 \mathrm{MPa}$ PEG treatment, which could be due to 
the greater $\mathrm{Pb}$ tolerance of $M$. flavida in comparison to the non-metallicolous $M$. incana (Houda et al., 2016).

CAT and APX are scavengers of $\mathrm{H}_{2} \mathrm{O}_{2}$, which is produced in peroxisomes, chloroplasts, and the cytosol (Sekmen et al., 2014). Activities of CAT and APX (Fig. 6) increased with increasing PEG exposure in the absence and presence of $\mathrm{Pb}$ in $M$. flavida, but $M$. incana showed differing responses to $\mathrm{Pb}$, with lower CAT activity in treatments of $\mathrm{PEG}$ without $\mathrm{Pb}$ compared to those treatments with $\mathrm{Pb}$. A similar result was reported for the $\mathrm{Cd} / \mathrm{Zn}$ accumulator Sedum alfredii, which had increased CAT and APX activity in roots exposed to $\mathrm{Pb}$ (Huang et al., 2012). ROS have a central role in response to stresses, both in signaling and through direct deleterious effects, and there are intimate tolerance responses in reaction to metals and drought. In a recent study involving overexpression of Glutathione s-transferase, Srivastava et al. (2019) observed a dual role for that gene in detoxification of heavy metals and in producing glutathione peroxidase (GPX)-like activity, both of which are essential for heavy metal and drought stress tolerance. Indeed, we suggest that other antioxidant enzymes also act in coordinated response to different stresses.

Finally, the regulatory networks that act in response to simultaneous stresses could have additive effects. For example, metal contamination in combination with drought may aggravate water stress or alleviate drought symptoms by induction of hydraulic safety (de Silva et al., 2012).

\section{Conclusions}

Growth responses showed that the metallicolous species $M$. flavida displayed greater $\mathrm{Pb}$ tolerance than the non-metallicolous species $M$. incana and consistently showed greater $\mathrm{Pb}$ accumulation in both roots and shoots. A possible reason for the superior $\mathrm{Pb}$ tolerance of $M$. flavida could be a reduced translocation factor (TF) under drought stress, which would decrease the $\mathrm{Pb}$ concentration in aerial parts of $M$. flavida. On the other hand, $\mathrm{Pb}$ could partly inhibit the negative effect of drought stress in the metallicolous $M$. flavida through accumulation of greater amounts of reducing sugars, phenolic compounds, and induction of CAT activity. Joint response elements, such as common and specific transcription factors, or response sequences, need to be determined in both species to identify interactive pathways that address different environmental abiotic stresses.

\section{Declarations}

\section{Acknowledgements}

We would like to thank the Graduate School of University of Isfahan for providing research facilities. We also thank our deceased colleague, Dr. Seyed Majid Ghaderian (Faculty of Biology, University of Isfahan, Isfahan, Iran), for contributing to the intellectual foundations for this research project.

\section{References}


Aebi, H., 1984. Catalase in vitro. Method. Enzymo. 105, 121-126.

Agrawal, L., Gupta, S., Mishra, S.K., Pandey, G., Kumar, S., Chauhan, P.S., Chakrabarty, D., Nautiyal, C.S., 2016. Elucidation of complex nature of PEG induced drought-stress response in rice root using comparative proteomics approach. Front. Plant Sci. 7, 1466.

Anjum, S.A., Xie, X.-y., Wang, L.-c., Saleem, M.F., Man, C., Lei, W., 2011. Morphological, physiological and biochemical responses of plants to drought stress. Afr. J. Agr. Res. 6, 2026-2032.

Asada, K., Takahashi, M., 1987. Production and scavenging of active oxygen in photosynthesis. In: Kyle, D.J., Osmond, B., Arntzen, C.J. (Eds.), Photoinhibition. Elsevier, Amsterdam, pp. 227-287.

Ashraf, M., Harris, P.J., 2013. Photosynthesis under stressful environments: an overview. Photosynthetica 51, 163-190.

Baker, A., 1987. Metal tolerance. New Phytol. 106, 93-111.

Basal, O., Szabó, A., Veres, S., 2020. Physiology of soybean as affected by PEG-induced drought stress. Curr. Plant Biol. 100135.

Bates, L.S., Waldren, R.P., Teare, I., 1973. Rapid determination of free proline for water-stress studies. Plant Soil 39, 205-207.

Boyd, R.S., Rajakaruna, N., 2013. Heavy metal tolerance. In: Gibson, D. (Ed), Oxford Bibliographies in Ecology. Oxford University Press, New York.

Cechin, I., Rossi, S., Oliveira, V., Fumis, T.d.F., 2006. Photosynthetic responses and proline content of mature and young leaves of sunflower plants under water deficit. Photosynthetica 44, 143.

Cruz de Carvalho, M.H., 2008. Drought stress and reactive oxygen species: production, scavenging and signaling. Plant Signal Behav. 3, 156-165.

Cvikrová, M., Gemperlová, L., Martincová, O., Vanková, R., 2013. Effect of drought and combined drought and heat stress on polyamine metabolism in proline-over-producing tobacco plants. Plant Physiol. Bioch. 73, 7-15.

Dalla Vecchia, F., La Rocca, N., Moro, I., De Faveri, S., Andreoli, C., Rascio, N., 2005. Morphogenetic, ultrastructural and physiological damages suffered by submerged leaves of Elodea canadensis exposed to cadmium. Plant Sci. 168, 329-338.

de Silva, N.D.G., Cholewa, E., Ryser, P., 2012. Effects of combined drought and heavy metal stresses on xylem structure and hydraulic conductivity in red maple (Acer rubrum L.). J. Exp. Bot. 63, 5957-5966.

Ekmekçi, Y., Tanyolaç, D., Ayhan, B., 2009. A crop tolerating oxidative stress induced by excess lead: maize. Acta Physiol. Plant. 31, 319-330. 
Ernst, W., 1988. Response of plants and vegetation to mine tailings and dredged materials. In: Salomons, W., Förstner, U. (Eds.), Chemistry and Biology of Solid Waste. Springer, Berlin, Heidelberg, pp. 54-69.

Fahr, M., Laplaze, L., El Mzibri, M., Doumas, P., Bendaou, N., Hocher, V., Bogusz, D., Smouni, A., 2015. Assessment of lead tolerance and accumulation in metallicolous and non-metallicolous populations of Hirschfeldia incana. Environ. Exp. Bot. 109, 186-192.

Farooq, M., Hussain, M., Wahid, A., Siddique, K., 2012. Drought stress in plants: an overview. In: Aroca, R. (Eds), Plant Responses to Drought Stress. Springer, Berlin, Heidelberg, pp. 1-33.

Farooq, M., Wahid, A., Kobayashi, N., Fujita, D., Basra, S., 2009. Plant drought stress: effects, mechanisms and management. Agron. Sustain. Dev. 29, 185-212.

Ghasemi, Z., Ghaderian, S.M., Monterroso, C., Kidd, P.S., 2018. Improving the growth of Nihyperaccumulating plants in serpentine quarry tailings. Int. J. Phytoremediat. 20, 699-708.

Ginn, B.R., Szymanowski, J.S., Fein, J.B., 2008. Metal and proton binding onto the roots of Fescue rubra. Chem. Geol. 253, 130-135.

Grieve, C., Grattan, S., 1983. Rapid assay for determination of water soluble quaternary ammonium compounds. Plant Soil 70, 303-307.

Gupta, D., Huang, H., Corpas, F., 2013. Lead tolerance in plants: strategies for phytoremediation. Environ. Sci. Pollut. R. 20, 2150-2161.

Hajihashemi, S., Sofo, A., 2018. The effect of polyethylene glycol-induced drought stress on photosynthesis, carbohydrates and cell membrane in Stevia rebaudiana grown in greenhouse. Acta Physiol. Plant. 40, 142.

Hakeem, K.R., Alharby, H.F., Rehman, R., 2019. Antioxidative defense mechanism against lead-induced phytotoxicity in Fagopyrum kashmirianum. Chemosphere 216, 595-604.

Heidari Dehno, A., Mohtadi, A., 2018. The effect of different iron concentrations on lead accumulation in hydroponically grown Matthiola flavida Boiss. Ecol. Res. 33, 757-765.

Houda, Z., Bejaoui, Z., Albouchi, A., Gupta, D.K., Corpas, F.J., 2016. Comparative study of plant growth of two poplar tree species irrigated with treated wastewater, with particular reference to accumulation of heavy metals ( $\mathrm{Cd}, \mathrm{Pb}, \mathrm{As}$, and $\mathrm{Ni}$ ). Environ. Monit. Assess. 188, 99.

Huang, H., Gupta, D., Tian, S., Yang, X.-e., Li, T., 2012. Lead tolerance and physiological adaptation mechanism in roots of accumulating and non-accumulating ecotypes of Sedum alfredii. Environ. Sci. Pollut. R. 19, 1640-1651. 
Jaén-Molina, R., Caujapé-Castells, J., Reyes-Betancort, J.A., Akhani, H., Fernández-Palacios, O., de Paz, J.P., Febles-Hernández, R., Marrero-Rodríguez, Á., 2009. The molecular phylogeny of Matthiola R. Br. (Brassicaceae) inferred from ITS sequences, with special emphasis on the Macaronesian endemics. Mol. Phylogenet. Evol. 53, 972-981.

Kazakou, E., Dimitrakopoulos, P.G., Baker, A.J., Reeves, R.D., Troumbis, A.Y., 2008. Hypotheses, mechanisms and trade-offs of tolerance and adaptation to serpentine soils: from species to ecosystem level. Biol Rev Camb Philos Soc. 83, 495-508.

Kısa, D., Elmastaş, M., Öztürk, L., Kayır, Ö., 2016. Responses of the phenolic compounds of Zea mays under heavy metal stress. Appl. Biol. Chem. 59, 813-820.

Konečná, V., Yant, L., Kolář, F., 2020. The evolutionary genomics of serpentine adaptation. Front. Plant Sci. $11,2004$.

Krzesłowska, M., Lenartowska, M., Samardakiewicz, S., Bilski, H., Woźny, A., 2010. Lead deposited in the cell wall of Funaria hygrometrica protonemata is not stable-a remobilization can occur. Environ. Pollut. $158,325-338$.

Kumar, A., Prasad, M., Sytar, O., 2012. Lead toxicity, defense strategies and associated indicative biomarkers in Talinum triangulare grown hydroponically. Chemosphere 89, 1056-1065.

Kumar, A., Prasad, M.N.V., 2018. Plant-lead interactions: transport, toxicity, tolerance, and detoxification mechanisms. Ecotox. Environ. Safe. 166, 401-418.

Li, Y., Zhou, C., Huang, M., Luo, J., Hou, X., Wu, P., Ma, X., 2016. Lead tolerance mechanism in Conyza canadensis: subcellular distribution, ultrastructure, antioxidative defense system, and phytochelatins. J. Plant Res. 129, 251-262.

Lichtenthaler, H.K., Wellburn, A.R., 1983. Determinations of total carotenoids and chlorophylls a and b of leaf extracts in different solvents. Biochem. Soc. T. 11, 591-592.

Mahdavian, K., Ghaderian, S.M., Schat, H., 2016. Pb accumulation, Pb tolerance, antioxidants, thiols, and organic acids in metallicolous and non-metallicolous Peganum harmala L. under $\mathrm{Pb}$ exposure. Environ. Exp. Bot. 126, 21-31.

Mansfield, M.R., Pope, N.S., Mittelhauser, G.H., Rajakaruna, N., 2014. Diversity and soil-tissue elemental relations of vascular plants of Callahan Mine, Brooksville, Maine, USA. Rhodora 116, 283-322.

Michalak, A., 2006. Phenolic compounds and their antioxidant activity in plants growing under heavy metal stress. Pol. J. Environ. Stud. 15, 523.

Miri, H.R., Armin, M., 2013. The interaction effect of drought and exogenous application of glycine betaine on corn (Zea mays L.). Eur. J. Exp. Biol. 3, 197-206. 
Mohtadi, A., 2014. Heavy metal tolerance and accumulation in Matthiola flavida, a novel Iranian lead hyperaccumulator. Dissertation, Vrije Universiteit, Amsterdam.

Mohtadi, A., Ghaderian, S.M., Schat, H., 2012a. A comparison of lead accumulation and tolerance among heavy metal hyperaccumulating and non-hyperaccumulating metallophytes. Plant Soil 352, 267-276.

Mohtadi, A., Ghaderian, S.M., Schat, H., 2012b. Lead, zinc and cadmium accumulation from two metalliferous soils with contrasting calcium contents in heavy metal-hyperaccumulating and nonhyperaccumulating metallophytes: a comparative study. Plant Soil 361, 109-118.

Mohtadi, A., Ghaderian, S.M., Schat, H., 2013. The effect of EDDS and citrate on the uptake of lead in hydroponically grown Matthiola flavida. Chemosphere 93, 986-989.

Mondal, N.K., Das, C., Datta, J.K., 2015. Effect of mercury on seedling growth, nodulation and ultrastructural deformation of Vigna radiata (L) Wilczek. Environ. Monit. Assess. 187, 241.

Money, N.P., 1989. Osmotic pressure of aqueous polyethylene glycols: relationship between molecular weight and vapor pressure deficit. Plant Physiol. 91, 766-769.

Nabi, R.B.S., Tayade, R., Hussain, A., Kulkarni, K.P., Imran, Q.M., Mun, B.-G., Yun, B.-W., 2019. Nitric oxide regulates plant responses to drought, salinity, and heavy metal stress. Environ. Exp. Bot. 161, 120-133.

Okunlola, G.O., Olatunji, O.A., Akinwale, R.O., Tariq, A., Adelusi, A.A., 2017. Physiological response of the three most cultivated pepper species (Capsicum spp.) in Africa to drought stress imposed at three stages of growth and development. Sci. Hortic-Amsterdam 224, 198-205.

Osakabe, Y., Osakabe, K., Shinozaki, K., Tran, L.-S.P., 2014. Response of plants to water stress. Front. Plant Sci. 5, 86.

Pourrut, B., Shahid, M., Douay, F., Dumat, C., Pinelli, E., 2013. Molecular mechanisms involved in lead uptake, toxicity and detoxification in higher plants. In: Gupta, D., Corpas, F., Palma, J. (Eds.), Heavy Metal Stress in Plants. Springer, Berlin, Heidelberg, pp. 121-147.

Rascio, N., Navari-Izzo, F., 2011. Heavy metal hyperaccumulating plants: how and why do they do it? And what makes them so interesting? Plant Sci. 180, 169-181.

Salehi-Eskandari, B., Ghaderian, S.M., Schat, H., 2017. The role of nickel (Ni) and drought in serpentine adaptation: contrasting effects of $\mathrm{Ni}$ on osmoprotectants and oxidative stress markers in the serpentine endemic, Cleome heratensis, and the related non-serpentinophyte, Cleome foliolosa. Plant Soil 417, 183195.

Salehi-Eskandari, B., Ghaderian, S.M., Schat, H., 2018. Differential interactive effects of the $\mathrm{Ca} / \mathrm{Mg}$ quotient and PEG-simulated drought in Alyssum inflatum and Fortuynia garcinii. Plant Soil 428, 213-222. 
Sarwar, G.R., Qaiser, M., 2012. Distribution pattern, ecology and endemism of family Crassulaceae in Pakistan and Kashmir. Pak. J. Bot. 44, 2055-2061.

Sekmen, A.H., Ozgur, R., Uzilday, B., Turkan, I., 2014. Reactive oxygen species scavenging capacities of cotton (Gossypium hirsutum) cultivars under combined drought and heat induced oxidative stress. Environ. Exp. Bot. 99, 141-149.

Selby, J.P., Jeong, A.L., Toll, K., Wright, K.M., Lowry, D.B., 2014. Methods and discoveries in the pursuit of understanding the genetic basis of adaptation to harsh environments in Mimulus. In Rajakaruna, N., Boyd, R.S., Harris T.B. (Eds.), Plant ecology and evolution in harsh environments. New York, NY: Nova Science Publishers Inc.

Selby, J.P., Willis, J.H., 2018. Major QTL controls adaptation to serpentine soils in Mimulus guttatus. Mol. Ecol. 27, 5073-5087.

Sharma, A., Kumar, V., Shahzad, B., Ramakrishnan, M., Sidhu, G.P.S., Bali, A.S., Handa, N., Kapoor, D., Yadav, P., Khanna, K., 2020. Photosynthetic response of plants under different abiotic stresses: a review. J. Plant Growth Regul. 39, 509-531.

Singh, S., Parihar, P., Singh, R., Singh, V.P., Prasad, S.M., 2016. Heavy metal tolerance in plants: role of transcriptomics, proteomics, metabolomics, and ionomics. Front. Plant Sci. 6, 1143.

Somogyi, M., 1952. Notes on sugar determination. J. Biol. Chem. 195, 19-23.

Srivastava, D., Verma, G., Chauhan, A.S., Pande, V., Chakrabarty, D., 2019. Rice (Oryza sativa L.) tau class glutathione S-transferase (OsGSTU30) overexpression in Arabidopsis thaliana modulates a regulatory network leading to heavy metal and drought stress tolerance. Metallomics 11, 375-389.

Stiborova, M., Doubravova, M., Brezinova, A., Friedrich, A., 1986. Effect of heavy metal ions on growth and biochemical characteristics of photosynthesis of barley (Hordeum vulgare L.). Photosynthetica (Praha) 20, 418-425.

Velioglu, Y., Mazza, G., Gao, L., Oomah, B., 1998. Antioxidant activity and total phenolics in selected fruits, vegetables, and grain products. J. Agr. Food Chem. 46, 4113-4117.

Vodnik, D., Jentschke, G., Fritz, E., Gogala, N., Godbold, D., 1999. Root-applied cytokinin reduces lead uptake and affects its distribution in Norway spruce seedlings. Physiol. Plantarum (København. 1948) $106,75-81$.

Von Wettberg, E., Ray-Mukherjee, J., D’Adesky, N., Nesbeth, D., Sistla, S., 2014. The evolutionary ecology and genetics of stress resistance syndrome (SRS) traits: revisiting Chapin, Autumn and Pugnaire (1993). In: Rajakaruna, N., Boyd, R.S., Harris, T. (Eds.), Plant ecology and evolution in harsh environments, Nova Science Publishers, New York, pp. 201-226. 
Wang, Z., Li, G., Sun, H., Ma, L., Guo, Y., Zhao, Z., Gao, H., Mei, L., 2018. Effects of drought stress on photosynthesis and photosynthetic electron transport chain in young apple tree leaves. Biol. Open 7.

Wanger, G., 1979. Content and vacuole/extra vacuole distribution of neutral sugars, free amino acids, and anthocyanins in protoplasts. Plant Physiol. 64, 88-93.

Wani, A.L., Ara, A., Usmani, J.A., 2015. Lead toxicity: a review. Interdiscip. Toxicol. 8, 55-64.

You, J., Chan, Z., 2015. ROS regulation during abiotic stress responses in crop plants. Front. Plant Sci. 6, 1092.

Zhang, C., Shi, S., Wang, B., Zhao, J., 2018. Physiological and biochemical changes in different droughttolerant alfalfa (Medicago sativa L.) varieties under PEG-induced drought stress. Acta Physiol. Plant. 40, 25.

Zheng, L., Peer, T., Seybold, V., Lütz-Meindl, U., 2012. Pb-induced ultrastructural alterations and subcellular localization of $\mathrm{Pb}$ in two species of Lespedeza by TEM-coupled electron energy loss spectroscopy.

Environ. Exp. Bot. 77, 196-206.

Zulfiqar, U., Farooq, M., Hussain, S., Maqsood, M., Hussain, M., Ishfaq, M., Ahmad, M., Anjum, M.Z., 2019. Lead toxicity in plants: Impacts and remediation. J. Environ. Manage. 250, 109557.

\section{Figures}


A
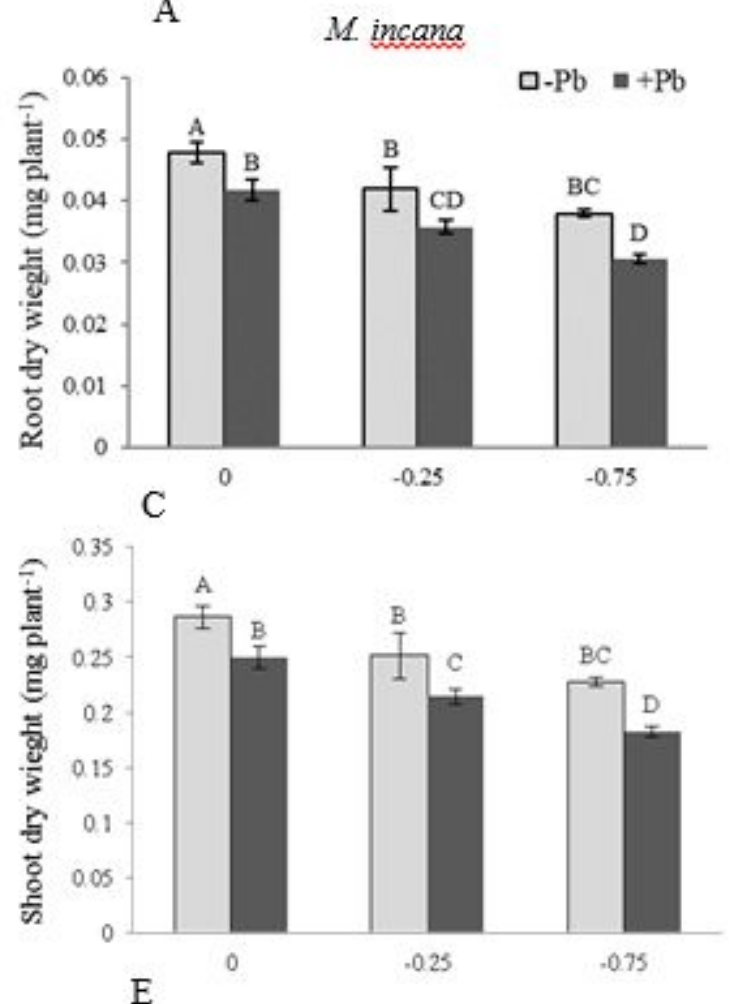

E

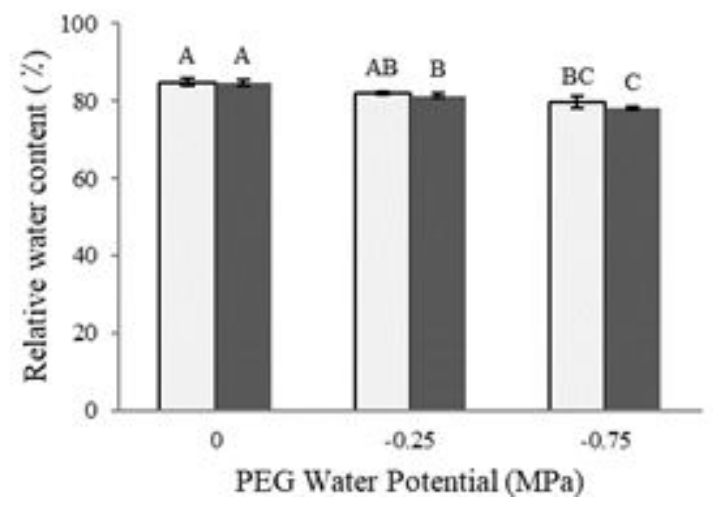

B

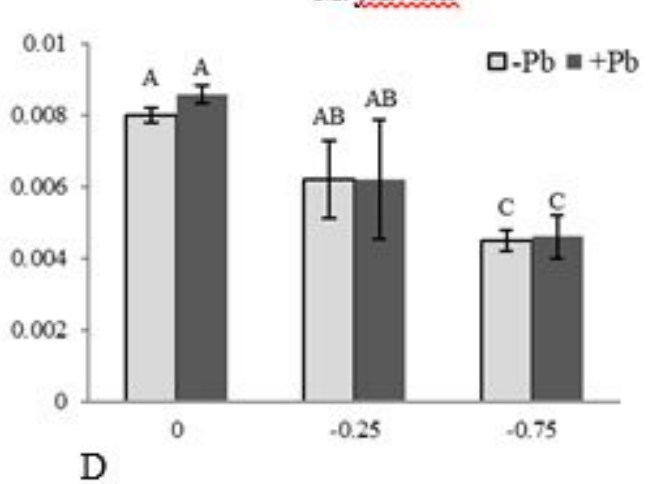

D
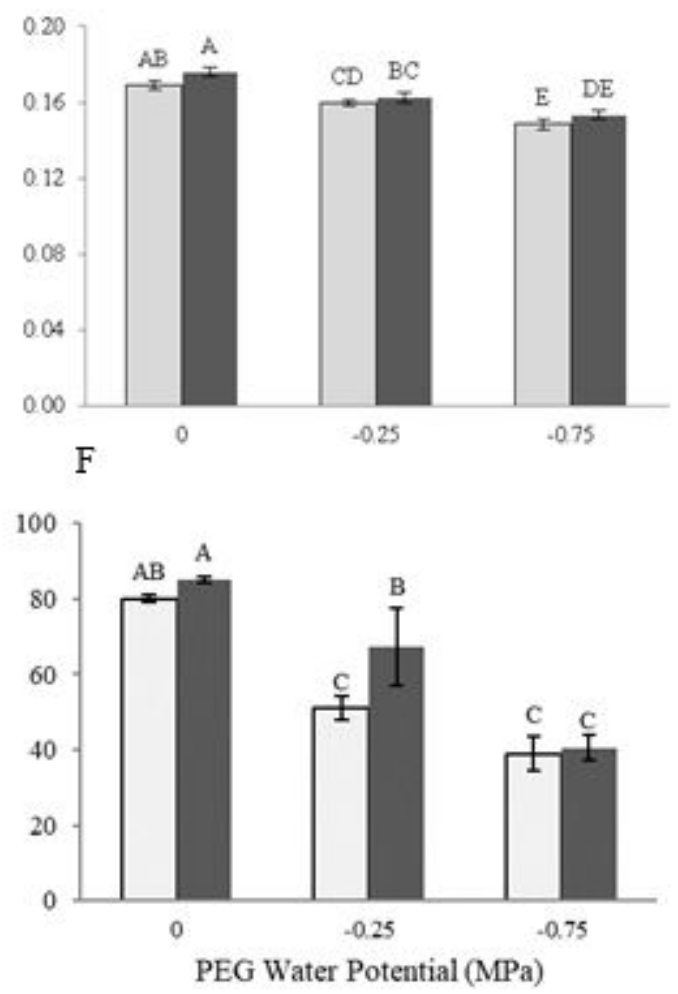

Figure 1

Effect of drought stress induced by PEG on root dry weight, shoot dry weight, and relative water content (\%) in Matthiola incana (A, C, E) and M. flavida (B, D, F), exposed to no-Pb added (gray bars) or Pb added as $\mathrm{Pb}(\mathrm{NO3}) 2$ (black bars) treatments for 14 days. Significant differences between means $(\mathrm{P}<0.05)$ are indicated by different letters. 
A
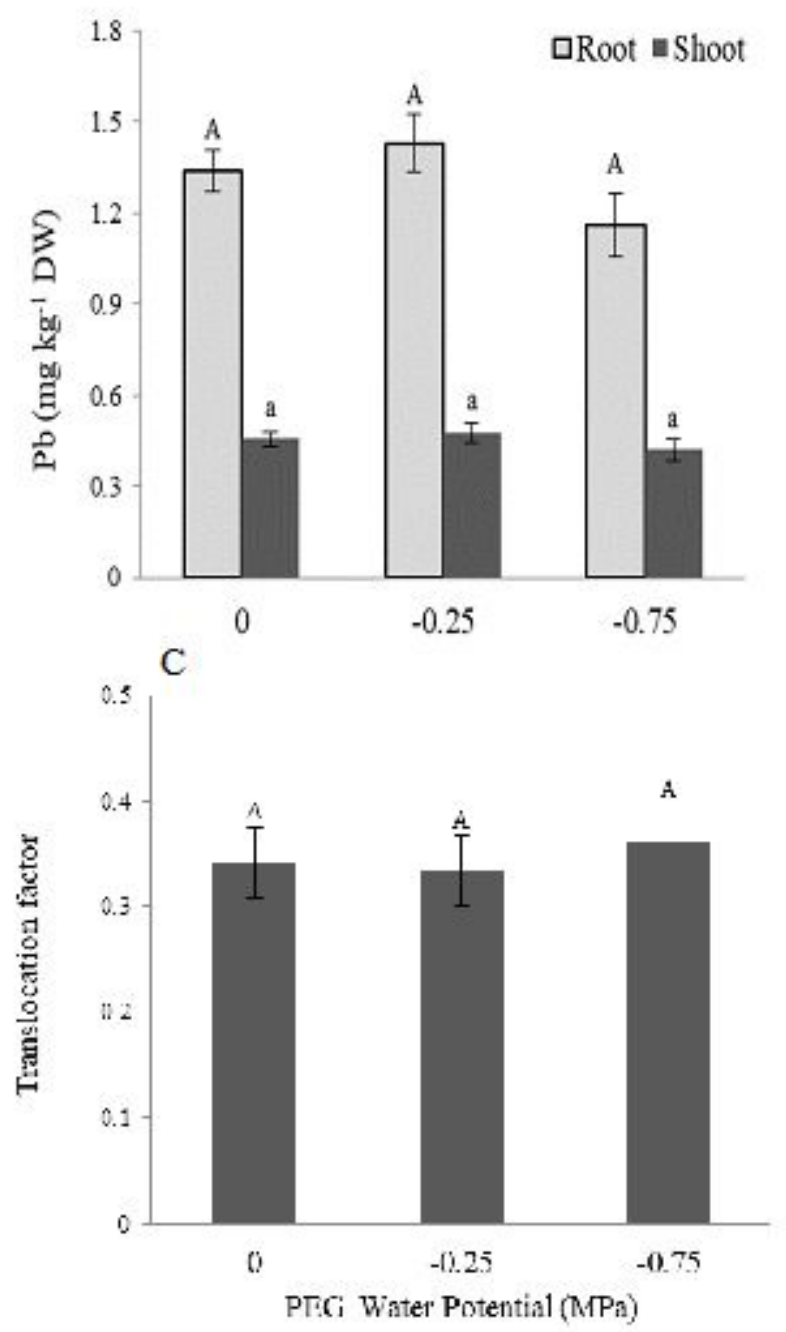

B
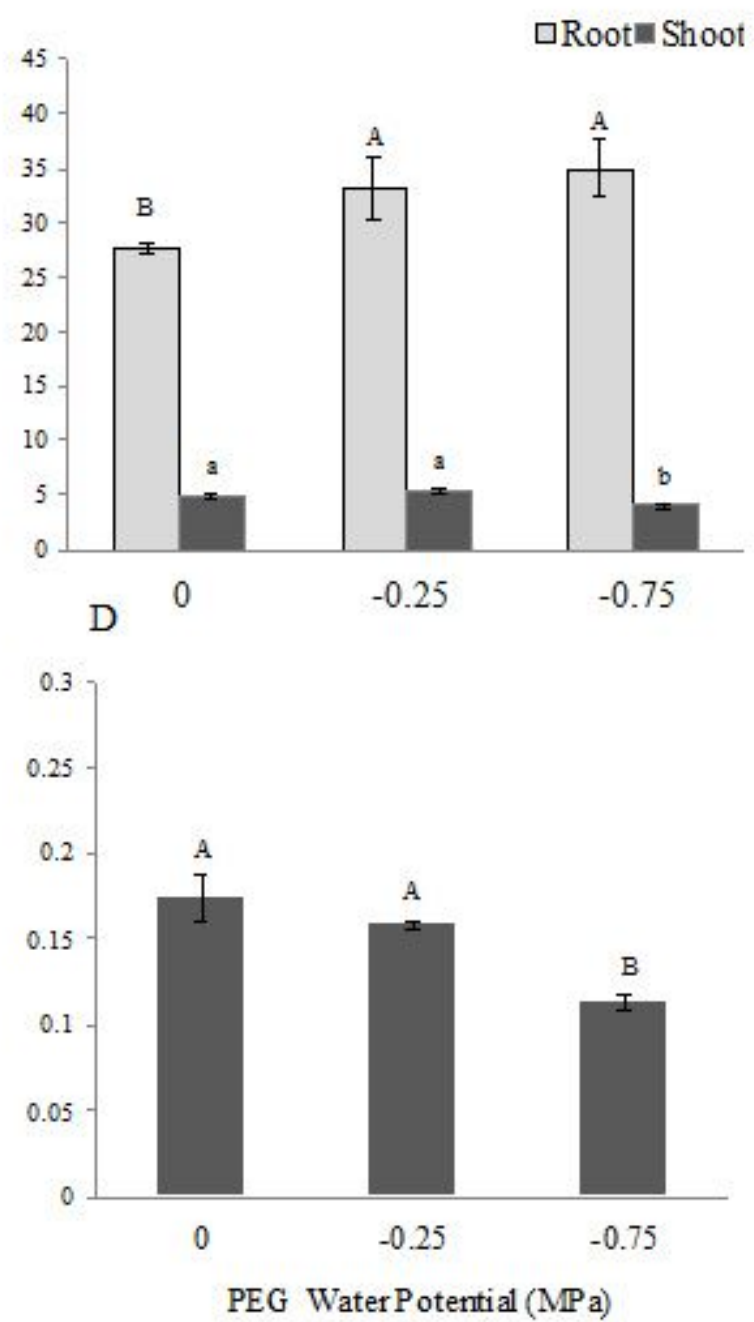

Figure 2

Effect of drought stress induced by PEG on Pb concentration in roots (gray bars in A, B) and shoots (black bars in A, B) and Pb translocation factors (C, D) in Matthiola incana and M. flavida exposed to the Pb-added treatment for 14 days. Significant differences between means $(P<0.05)$ are indicated by different letters. 
A
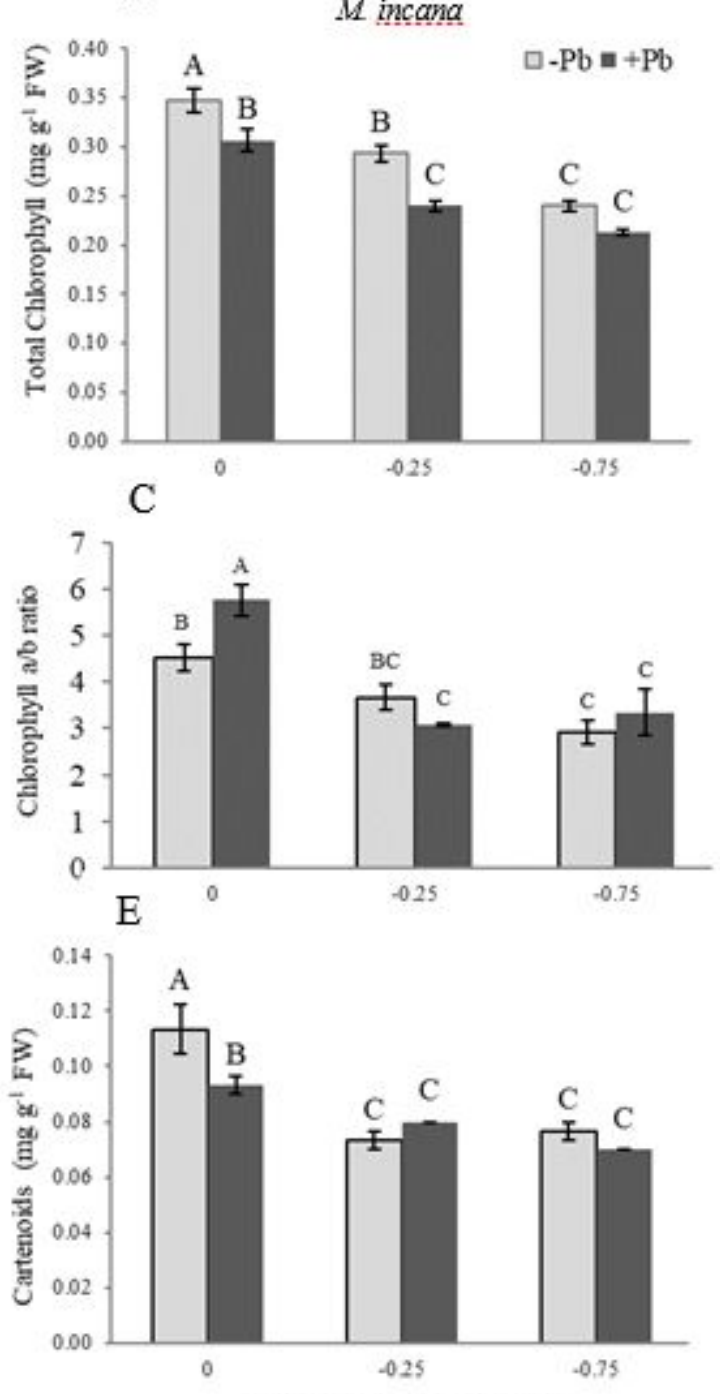

PEG Water Potential (MPa)
B $\quad$ M. flavida

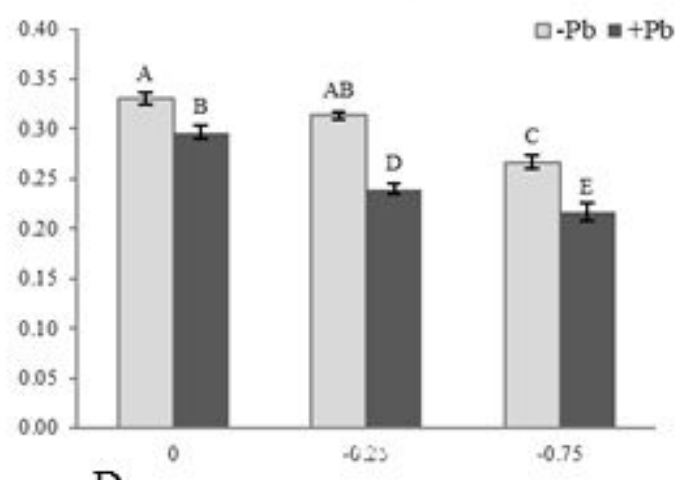

$\mathrm{D}$
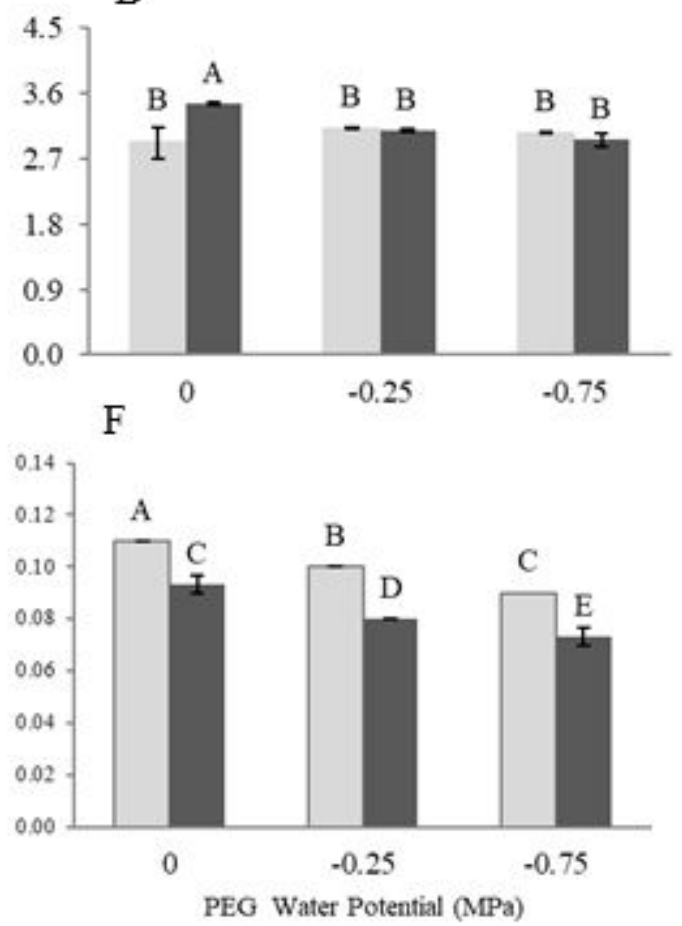

Figure 3

Effect of drought stress induced by PEG on concentration of total chlorophyll (A, B), chlorophyll a/b ratio $(C, D)$, and concentration of carotenoids $(E, F)$ in Matthiola incana and $M$. flavida exposed to no $\mathrm{Pb}$-added (gray bars) or $\mathrm{Pb}$-added as $\mathrm{Pb}(\mathrm{NO}) 2$ (black bars) treatments for 14 days. Significant differences between means $(P<0.05)$ are indicated by different letters. 

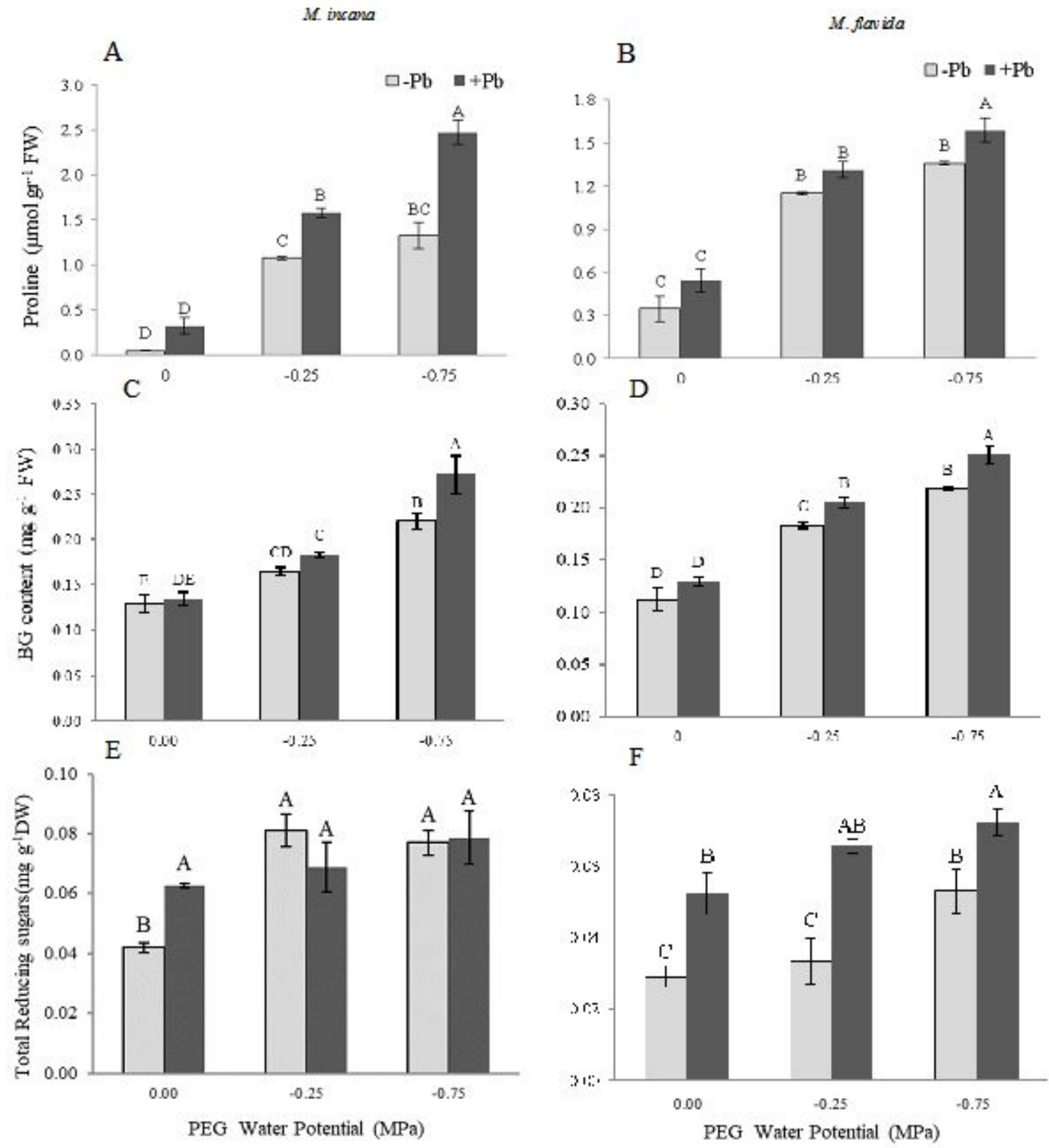

Figure 4

Effect of drought stress induced by PEG on proline, glycine betaine (GB), and Total Reducing Sugars (TRS) concentrations in Matthiola incana (A, C, E) and M. flavida (B, D, F) exposed to no Pb-added (gray bars) or $\mathrm{Pb}$-added as $\mathrm{Pb}(\mathrm{NO}) 2$ (black bars) treatments for 14 days. Significant differences between means $(P<0.05)$ are indicated by different letters. 

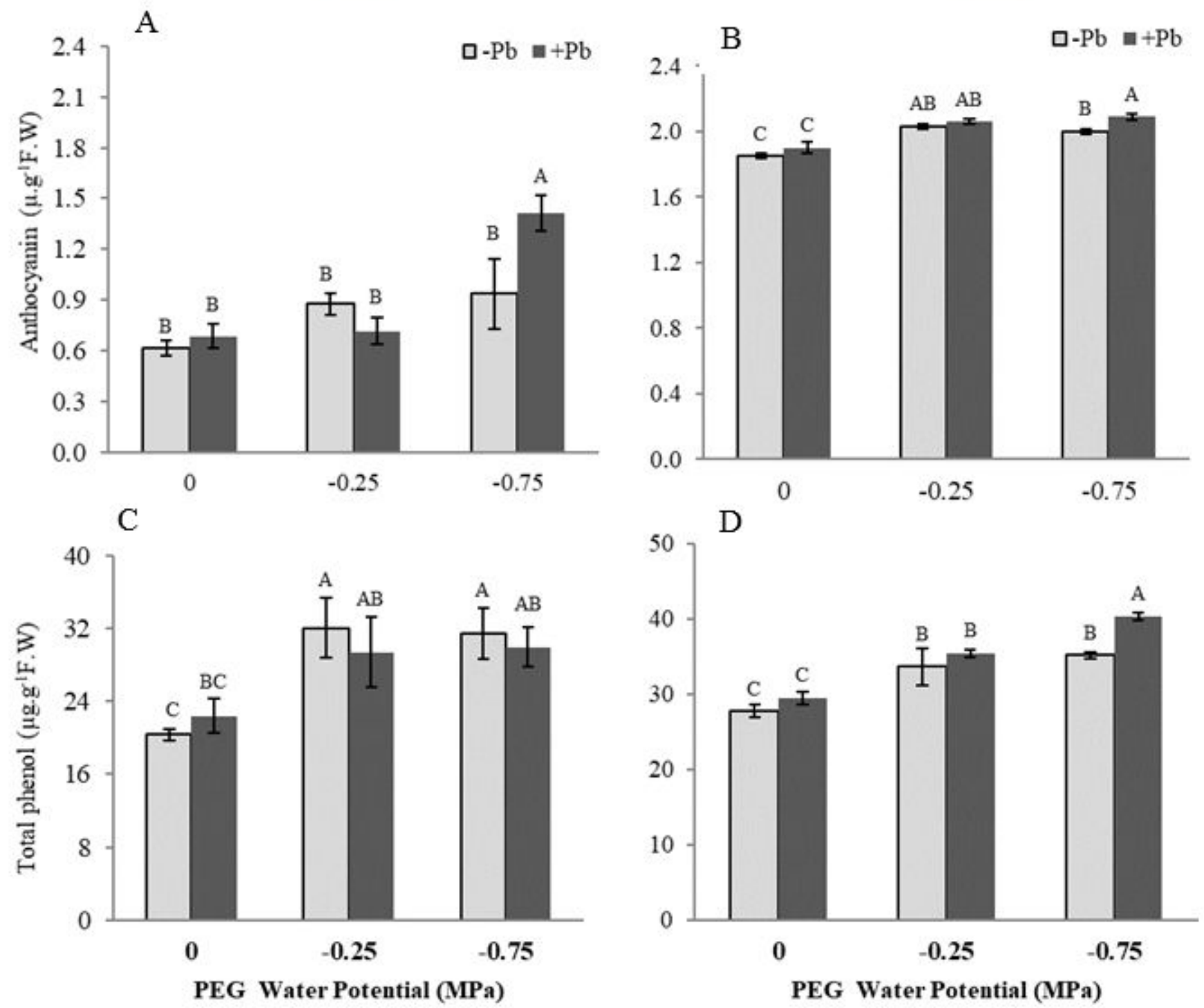

Figure 5

Effect of drought stress induced by PEG on anthocyanins and total phenolic contents in Matthiola incana $(\mathrm{A}, \mathrm{C})$ and $\mathrm{M}$. flavida $(\mathrm{B}, \mathrm{D})$ exposed to no $\mathrm{Pb}$-added (gray bars) or Pb-added as $\mathrm{Pb}(\mathrm{NO}$ ) 2 (black bars) treatments for 14 days. Significant differences between means $(P<0.05)$ are indicated by different letters. 
M. flavida
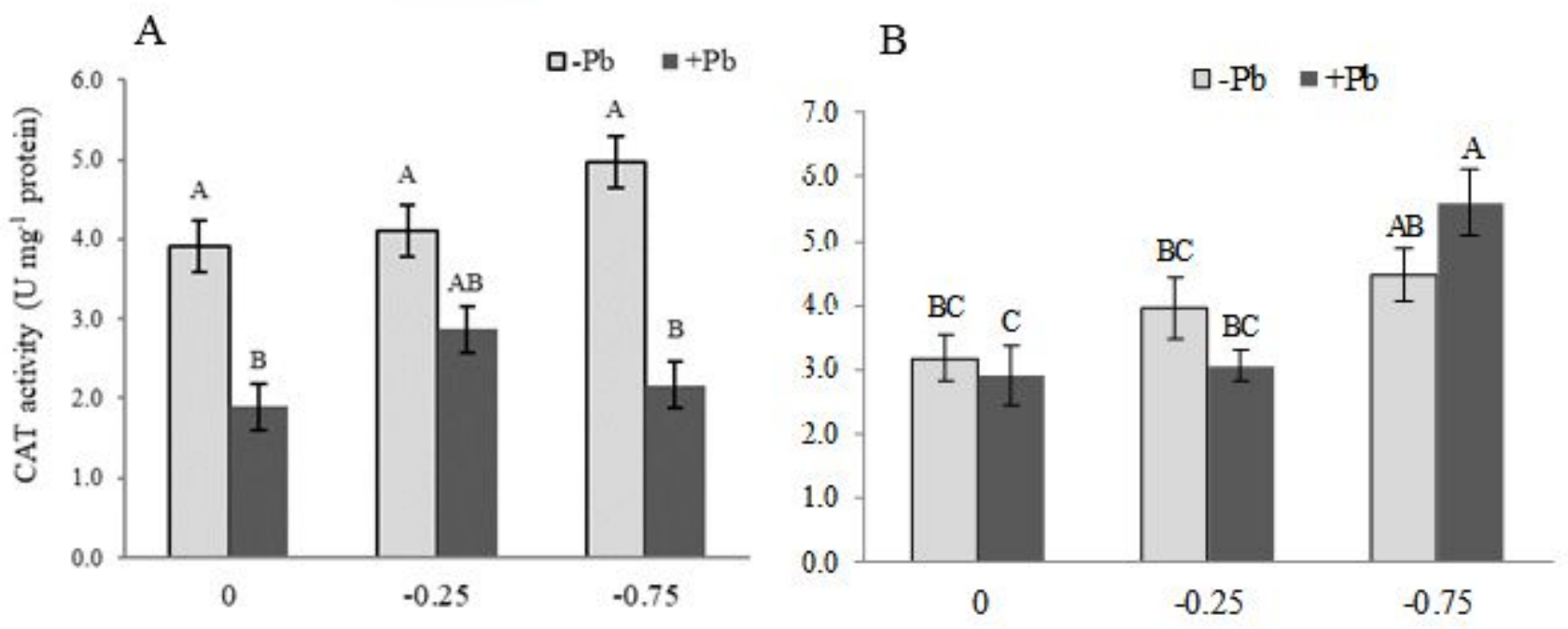

C

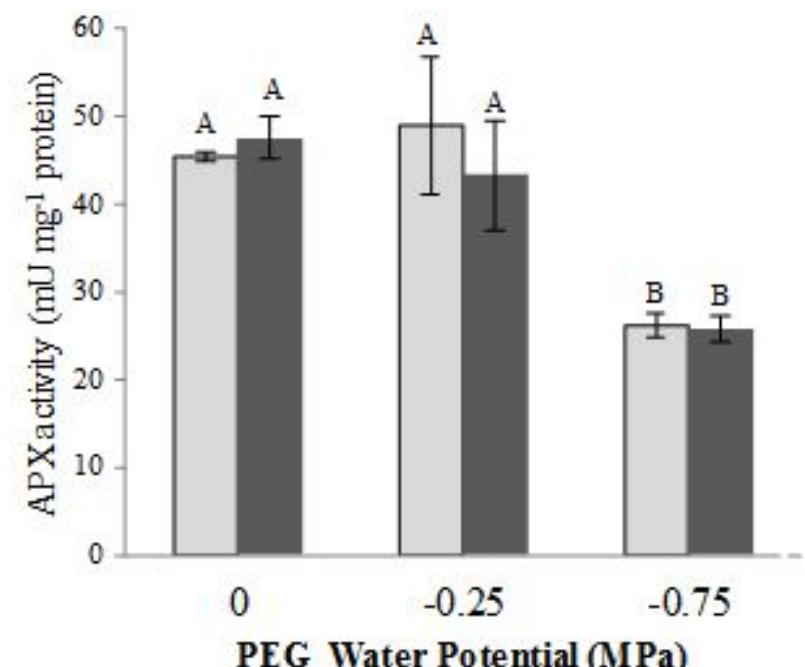

D

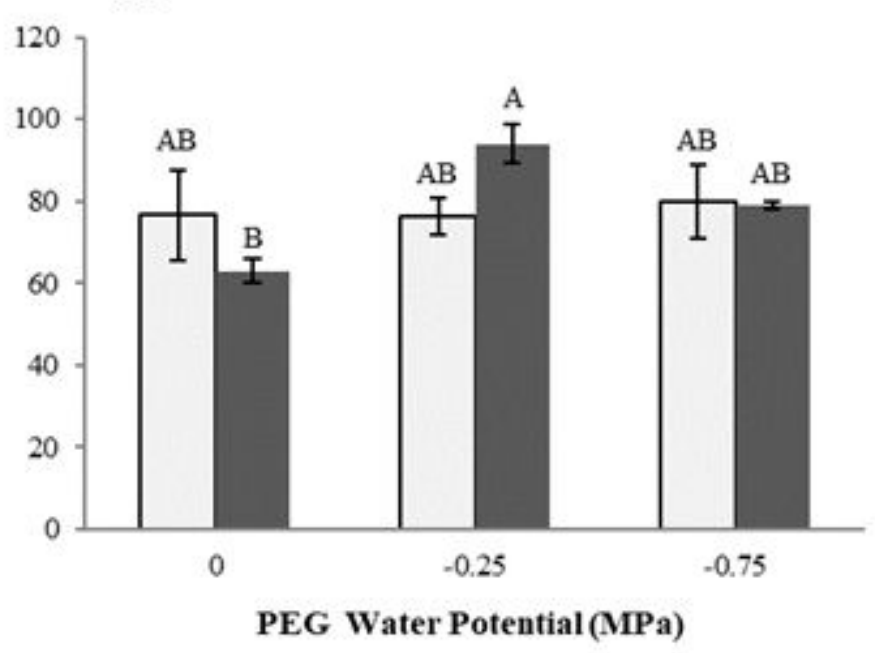

Figure 6

Effect of drought stress induced by PEG on activities of catalase (CAT) and ascorbate peroxidase (APX) in Matthiola incana and M. flavida exposed to no Pb-added (gray bars) or Pb-added as Pb(NO3)2 (black bars) treatments for 14 days. Significant differences between means $(P<0.05)$ are indicated by different letters. 